\title{
Effects of photoperiod and temperature on preimaginal development and summer diapause of Chrysocharis pubicornis (Zetterstedt) (Hymenoptera: Eulophidae), a pupal parasitoid of leafminers (Diptera: Agromyzidae)
}

\author{
Gustavo L. Baeza Larios, Kazuro OHNo* and Fumiki FuKuHARA ${ }^{\dagger}$ \\ Laboratory of Applied Entomology, Faculty of Agriculture, University of Miyazaki; Miyazaki 889-2192, Japan \\ (Received 12 June 2006; Accepted 14 November 2006)
}

\begin{abstract}
The preimaginal development of Chrysocharis pubicornis was studied at different temperatures and 14L:10D photoperiod. The lower developmental threshold was 7.4 and $7.2^{\circ} \mathrm{C}$, and the thermal constant was 297.4 and 307.5 degree-days for males and females, respectively. The effects of combinations of different temperatures and photoperiods on larval diapause induction and termination were also examined. Larval development showed a short-day type response affected by temperature. The percentage of individuals entering diapause increased with the temperature and photoperiod. The critical photoperiod for diapause induction was between 12 and $14 \mathrm{~h}$ at $25^{\circ} \mathrm{C}$, whereas at $15 \mathrm{~h}$ and $20^{\circ} \mathrm{C}$ the diapause rate did not reach $50 \%$ within the photoperiod range tested. Regardless of the photoperiod, diapause terminated at $15^{\circ} \mathrm{C}$ but was maintained at $25^{\circ} \mathrm{C}$. At $20^{\circ} \mathrm{C}, 90 \%$ of individuals terminated diapause at $12 \mathrm{~h}$ photoperiod but only $16 \%$ at $16 \mathrm{~h}$ photoperiod. A significant effect of the photoperiod on the post-diapause emergence pattern of wasps was observed at $15^{\circ} \mathrm{C}$. From these results, it is considered that summer diapause enables C. pubicornis to synchronize its occurrence with that of the garden pea leafminer, Chromatomyia horticola.
\end{abstract}

Key words: Chrysocharis pubicornis; Chromatomyia horticola; development threshold; summer diapause; critical photoperiod

\section{INTRODUCTION}

Chrysocharis pubicornis (Zetterstedt) is a solitary pupal endoparasitoid of Agromyzid leafminers, distributed in the Palearctic, Nearctic, Oriental, New Zealand and Austral-Asian regions (Hansson, 1987). Several Agromyzid species have been recorded in Japan as C. pubicornis hosts (Kamijo, 1978; Ikeda, 1996), among which the garden pea leafminer Chromatomyia horticola Goreau is likely to be the main host since $C$. pubicornis is usually one of the dominant species in the parasitoid complex of C. horticola (Mitsuda and Yamasaki, 2003). The other dominant species in the C. horticola parasitoid complex, i.e. Diglyphus isaea and Chrysocharis pentheus, have been studied to some extent (Sugimoto and Masaki, 1979; Sugimoto et al., 1982; Minkenberg, 1990; Bazzocchi et al., 2003); however, little is known about C. pubicornis behavior and ecology.

During initial rearing trials to study this parasitoid species, we found that development seemed to stop indefinitely in a significant proportion of mature larvae when reared under conditions typical of summer (i.e. long daylength and high temperature), whereas individuals reared at short daylength and low temperature developed directly into adults without apparent interruption in their development. This suggested that $C$. pubicornis enters summer diapause at the larval stage inside the host puparium.

Summer diapause or estivation is induced before the height of summer, terminated and followed by reproductive, developmental, or feeding activities in autumn or winter. It occurs among different orders of insects, in a variety of climates, and is associated with a specific developmental stage for a particular species. Its primary role is to synchro-

\footnotetext{
* To whom correspondence should be addressed at: E-mail: ohnok@plant.miyazaki-u.ac.jp

${ }^{\dagger}$ Present address: Graduate School of Bioresource and Bioenvironmental Sciences, Kyushu University, Fukuoka 812-8581, Japan DOI: $10.1303 / \mathrm{aez} .2007 .189$
} 
nize the life cycle of the insect with the cycle of food availability (Masaki, 1980).

Among parasitic Hymenoptera, summer diapause has been reported in the families Mymaridae (Tsukada, 1999), Ichneumonidae (Radcliffe and Flanders, 1998 and references therein), Scelionidae (Dangerfield et al., 2001) and Aphidiidae (Polgar and Hardie, 2000 and references therein). In addition, Takada and Kamijo (1979) mentioned that the Braconid Dacnusa nipponica, also a parasitoid of C. horticola, spends the summer in dormancy when the host is absent in the field, but information on the conditions that regulate such dormancy is lacking. Nevertheless, there has been no report of C. pubicornis summer diapause in field studies where this parasitoid species has been collected from leafminer-infested leaves (e.g. Cameron, 1939; Takada and Kamijo, 1979; Cornelius and Godfray, 1984; Kato, 1996; Mitsuda and Yamasaki, 2003). We are also unaware of any report of summer diapause in other Eulophid leafminer parasitoids. Therefore, to obtain insight into the ecology of C. pubicornis, we conducted this study to obtain basic information about its development and to determine the conditions that induce, maintain, and terminate summer diapause.

\section{MATERIALS AND METHODS}

Insects. Adult $C$. horticola were obtained from infested garden pea (Pisum sativum L. var. sativum) leaves collected at several locations in Miyazaki City from March to May, 2002. Flies were then reared at $22^{\circ} \mathrm{C}, 16 \mathrm{~L}: 8 \mathrm{D}$ photoperiod and 40-60\% RH using potted kidney bean (Phaseolus vulgaris L.) as the host plant. The flies had been reared for five generations by the time the experiments started.

To obtain host pupae for the experiments, kidney bean leaves were exposed to adult flies in the stock cage for $1-3 \mathrm{~h}$ and subsequently held at the conditions described above. By the tenth day after infestation, most individuals were newly formed (less than 1 day old) pupae, which is the stage used in the experiments.

C. pubicornis wasps were obtained from fieldcollected garden pea leaves infested with $C$. horticola by keeping the leaves in an emergence device (Ohno et al., 1999). The wasps were reared at $25^{\circ} \mathrm{C}$ and 16L:8D using laboratory-reared C. horticola pupae as the host. Under the above conditions, some individuals developed into adults, while others entered diapause at the larval stage (see details in Results); therefore, to avoid artificial selection, both diapausing and nondiapausing individuals were pooled to maintain the culture. The wasps had been reared for approximately four generations by the time the experiments started.

To obtain parasitized pupae for the experiments, kidney bean plants with only cotyledon leaves bearing a maximum of 20 newly formed (less than 1 day old) $C$. horticola pupae per leaf were selected from the rearing room and placed in clear $350 \mathrm{ml}$ polyethylene terephthalate beverage bottles (PET bottle) filled with tap water. The host puparia were exposed to 3- to 5-day-old mated C. pubicornis females in a clear plastic cage for $2-6 \mathrm{~h}$. The wasps used for parasitization were only those that emerged as adults when reared at $25^{\circ} \mathrm{C}$ and 16L:8D (nondiapausing individuals).

Effect of temperature on the developmental period. To obtain basic information on the biology of C. pubicornis, we first determined the effect of temperature on the developmental period of immature stages (egg-larva, pupa, egg-adult) by rearing wasps at five constant temperatures $(15,17.5,20$, 22.5, and $25^{\circ} \mathrm{C}$ ) and a 14L:10D photoperiod. Kidney bean plants bearing $C$. horticola puparia parasitized by $C$. pubicornis were obtained as described above and exposed to experimental temperatures in a temperature gradient chamber. Preliminary experiments suggested that as temperature increases, an increasing percentage of larvae will not develop into adults. Therefore, to compensate for that difference and obtain a similar number of emerging adults at each temperature tested, the number of parasitized puparia reared was increased by $10-20 \%$ for each temperature. The parasitized host puparia were checked everyday under a binocular microscope to determine the parasitoid developmental stage, and the date of pupation was recorded for each individual. Two days before the first adult parasitoid was expected to emerge at each of the test temperatures (based on preliminary experiments), the host puparia with parasitoid pupae were removed from within the leaf tissue and placed individually in clear gelatin capsules. The capsules were kept in Petri dishes in the same chamber and were checked daily for parasitoid emergence, upon which the date and sex of the 
emerging parasitoids were recorded. About 100 days after the experiment started, puparia from which no adult wasp emerged were dissected to check for unemerged adults or the mortality of immature stages. The lengths of the developmental period were used to calculate the lower developmental threshold and thermal constant for this parasitoid species.

Effects of photoperiod and temperature on diapause induction. We reared wasps at combinations of three temperatures $\left(15,20\right.$ and $\left.25^{\circ} \mathrm{C}\right)$ and photoperiods (12L:12D, 14L:10D, and $16 \mathrm{~L}: 8 \mathrm{D})$ to determine the effects of photoperiod and temperature on the diapause induction rate. Data for treatments at 14L:10D photoperiod were obtained from the previous experiment.

Kidney bean plants bearing $C$. horticola puparia parasitized by C. pubicornis were obtained as described above. The leaves were divided into groups with an approximately equal number of pupae according to the number of treatments to be tested. Each group was randomly assigned to one of the treatments and transferred to an incubator with appropriate settings. Each temperature-photoperiod combination was replicated six to nine times, with each replication consisting of an average of 55 host pupae distributed in 4 leaves. The leaves were checked every two or three days to observe larval and pupal parasitoid development. The number of emerged wasps and their sex were recorded everyday as described in the previous experiment. Following emergence of the first adult, the leaves held at 15,20 and $25^{\circ} \mathrm{C}$ were checked with the same frequency for periods of 40,30 and 20 days, respectively, and all newly formed pupae were also removed and placed in capsules. After such period elapsed, the host puparia remaining in the leaves were dissected and all living parasitoid larvae found were considered to be in diapause. The puparia in capsules were also checked and those from which no parasitoid emerged were dissected. Parasitoid pupae and unemerged adults found during dissection were also considered as nondiapausing individuals. The diapause induction rate (\% DI) was calculated as below.

$\% \mathrm{DI}=[$ No. of diapausing larvae/(No. of diapausing individuals + No. of nondiapausing individuals) $] \times 100$

Effects of photoperiod and temperature on diapause termination. To examine the effects of photoperiod and temperature on the termination of larval diapause, we exposed diapausing individuals to combinations of three constant temperatures (15, 20 and $25^{\circ} \mathrm{C}$ ) and two photoperiods (12L:12D and 16L:8D). Kidney bean leaves holding $C$. horticola puparia parasitized by C. pubicornis were prepared as in the previous experiment. To obtain diapausing larvae, these leaves were kept at $25^{\circ} \mathrm{C}$ and $16 \mathrm{~L}: 8 \mathrm{D}$ until all the nondiapausing wasps emerged. The leaves, now holding diapausing parasitoid larvae, were then stored for approximately three months under the same conditions. The leaves were then divided into groups according to the number of treatments (six temperature-photoperiod combinations). All treatments were replicated six times, each replication consisting of 2-4 leaves with c.a. 40 diapausing pupae. To apply the treatments, each group of leaves was placed in a clear plastic container with a nylon mesh-screened window on the lid, and the containers were placed in an incubator at the appropriate temperature and photoperiod settings. The leaves were checked daily to determine the day of pupation. The sex and emergence date of adults at 15,20 , and $25^{\circ} \mathrm{C}$ were recorded for 40,30 and 20 days, respectively. Once the emergence period elapsed, all puparia in the leaves were dissected to check for diapausing larvae. Pupation was considered the criterion for diapause termination, thus all parasitoid larvae found alive during dissection were considered to be in diapause. The diapause termination rate $(\% \mathrm{DT})$ was calculated as follows:

$\% \mathrm{DT}=[$ No. of larvae that pupated/(No. of diapausing larvae + No. of nondiapausing larvae) $] \times 100$

\section{RESULTS}

\section{Effect of temperature on the developmental pe- riod}

At all temperatures tested, there were neither larval nor pupal deaths, nor adult wasps unable to emerge. Some individuals, however, entered diapause at certain temperatures and were excluded from analysis (diapause incidence data included in the diapause induction experiment). The mean development times of immature stages at each temperature examined are shown in Table 1. Development times of each stage were inversely related to temperature within the range tested. Total develop- 
Table 1. Developmental period (days, mean $\pm \mathrm{SD}$ ) of male and female Chrysocharis pubicornis reared on Chromatomyia horticola at different temperatures and 14L:10D photoperiodic regime

\begin{tabular}{clccccc}
\hline \multirow{3}{*}{ Sex } & & \multicolumn{5}{c}{ Temperature $\left({ }^{\circ} \mathrm{C}\right)$} \\
\cline { 3 - 7 } & & \multicolumn{7}{c}{ Stage } & 15.0 & 17.5 & 20.0 & 22.5 & 25.0 \\
\hline \multirow{2}{*}{ Male } & Egg+larva & $19.3 \pm 1.6$ & $15.0 \pm 1.1$ & $11.8 \pm 1.0$ & $9.9 \pm 1.2$ & $8.7 \pm 1.1$ \\
& Pupa & $18.7 \pm 1.4$ & $14.7 \pm 1.1$ & $12.5 \pm 0.9$ & $9.6 \pm 0.8$ & $8.2 \pm 0.7$ \\
& Total & $38.0 \pm 2.7$ & $29.7 \pm 1.6$ & $24.3 \pm 1.4$ & $19.5 \pm 1.3$ & $16.9 \pm 1.1$ \\
& & $(n=67)$ & $(n=51)$ & $(n=55)$ & $(n=74)$ & $(n=58)$ \\
Female & Egg+larva & $19.1 \pm 1.1$ & $15.2 \pm 1.5$ & $12.0 \pm 1.1$ & $9.6 \pm 0.9$ & $8.4 \pm 0.7$ \\
& Pupa & $19.1 \pm 1.2$ & $15.4 \pm 1.3$ & $12.7 \pm 1.0$ & $10.3 \pm 0.8$ & $8.5 \pm 0.6$ \\
& Total & $38.2 \pm 1.8$ & $30.6 \pm 2.3$ & $24.8 \pm 1.6$ & $19.9 \pm 1.3$ & $17.0 \pm 0.9$ \\
& & $(n=136)$ & $(n=66)$ & $(n=55)$ & $(n=55)$ & $(n=54)$ \\
\hline
\end{tabular}

Table 2. Linear regression equations of development rate $(V)$ on temperature $(T)$, lower developmental threshold and thermal constant for preimaginal stages of male and female $C$. pubicornis reared on $C$. horticola

\begin{tabular}{lcccc}
\hline Stage & $\begin{array}{c}\text { Regression } \\
\text { equation }\end{array}$ & $r^{2}$ & $\begin{array}{c}\text { Lower developmental } \\
\text { threshold }\left({ }^{\circ} \mathrm{C}\right)\end{array}$ & $\begin{array}{c}\text { Thermal constant } \\
\text { (degree-days) }\end{array}$ \\
\hline $\begin{array}{l}\text { Male }(n=305) \\
\text { Egg+larva }\end{array}$ & $V=0.0066 T-0.0472$ & $0.86^{* *}$ & 7.2 & 152.5 \\
$\quad$ Pupa & $V=0.0070 T-0.0546$ & $0.91^{* *}$ & 7.8 & 142.4 \\
$\quad$ Total & $V=0.0034 T-0.0253$ & $0.94^{* *}$ & 7.4 & 297.4 \\
Female $(n=366)$ & & & & 148.5 \\
Egg+larva & $V=0.0068 T-0.0506$ & $0.93^{* *}$ & 7.4 & 158.4 \\
Pupa & $V=0.0064 T-0.0447$ & $0.93^{* *}$ & 7.0 & 307.5 \\
Total & $V=0.0033 T-0.0237$ & $0.95^{* *}$ & 7.2 & \\
\hline
\end{tabular}

** Highly significant regression, $p<0.01$.

ment time (egg to adult) ranged from about 17 (at $25^{\circ} \mathrm{C}$ ) to 38 days $\left(\right.$ at $15^{\circ} \mathrm{C}$ ) and there were significant differences between sexes (ANOVA, $F_{1,669}=$ $36.04, p<0.001)$ with males emerging earlier than females. The developmental thresholds from egg to adult were $7.2^{\circ} \mathrm{C}$ for females and $7.4^{\circ} \mathrm{C}$ for males (Table 2). The thermal requirements of males and females were 297.4 and 307.5 degree-days, respectively.

\section{Effects of photoperiod and temperature on dia- pause induction}

Figure 1A shows the photoperiodic response of C. pubicornis at different temperatures. Larval development showed a short-day type response that was affected by temperature. Development was suppressed after larvae consumed all host tissue. Photoperiod and temperature had a highly significant effect on the induction of C. pubicornis larval diapause, and the effect of their interaction was significant (ANOVA, photoperiod: $F_{2,61}=46.44$, $p<0.001$; temperature: $F_{2,61}=60.83, \quad p<0.001$; photoperiod $\times$ temperature: $F_{4,61}=2.6, p<0.05$ ). At the lowest temperature and shortest photoperiod combination $\left(15^{\circ} \mathrm{C}\right.$ and $\left.12 \mathrm{~L}: 12 \mathrm{D}\right)$ the diapause rate was virtually $0 \%$. From that point, a growing percentage of larvae entered diapause as the photoperiod and temperature increased, with the highest value $(75 \%)$ obtained at $25^{\circ} \mathrm{C}$ and $16 \mathrm{~L}: 8 \mathrm{D}$. The critical photoperiod, at which $50 \%$ of individuals entered diapause, was between 12 and $14 \mathrm{~h}$ at $25^{\circ} \mathrm{C}$, whereas at $15^{\circ} \mathrm{C}$ and $20^{\circ} \mathrm{C}$, the mean diapause rate did not reach $50 \%$ regardless of the photoperiod. At 14L:10D and 16L:8D photoperiods there were no significant differences between diapause rates at $15^{\circ} \mathrm{C}$ and $20^{\circ} \mathrm{C}$, while at the three photoperiods examined, the diapause rate at $25^{\circ} \mathrm{C}$ was significantly higher than at other temperatures (Tukey HSD, $p<0.05$ ). 


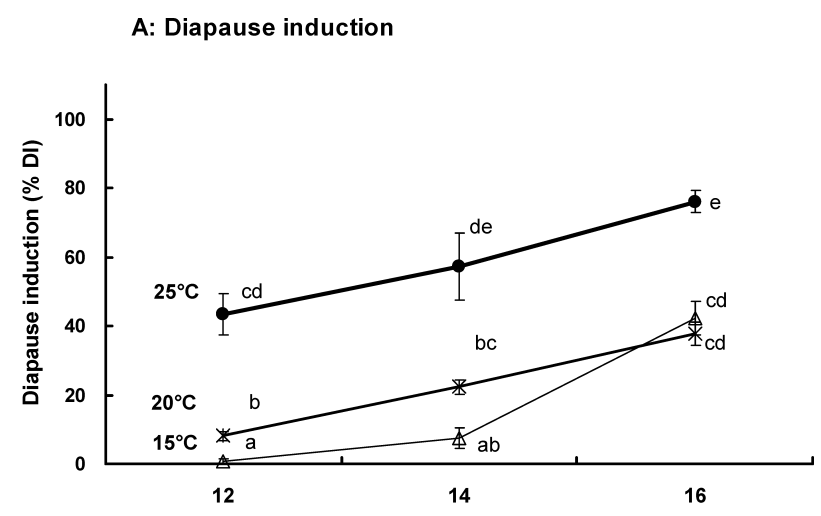

B: Diapause termination

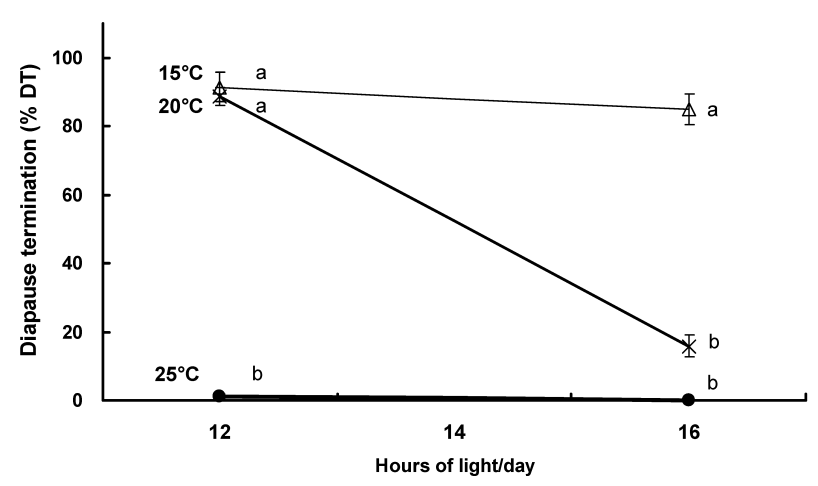

Fig. 1. Photoperiodic response (mean \pm SE) for larval diapause induction (A) and termination (B) of C. pubicornis at three constant temperatures. Percentage data were transformed to arcsin prior to analysis. Means with the same letter are not significantly different (Tukey HSD, $p<0.05$ ).

\section{Effects of photoperiod and temperature on dia- pause termination}

Figure 1B shows the effect of photoperiod and temperature on the termination of $C$. pubicornis larval diapause. Regardless of the photoperiod, diapause terminated in most larvae held at $15^{\circ} \mathrm{C}$, but was maintained at $25^{\circ} \mathrm{C}$. It was only at $20^{\circ} \mathrm{C}$ that photoperiod affected the diapause termination rate; almost $90 \%$ of larvae completed diapause with a short photoperiod (12L:12D) but only $16 \%$ with a long photoperiod (16L:8D). Photoperiod, temperature, and the interaction of these two factors had a highly significant effect on diapause termination (ANOVA, photoperiod: $F_{1,32}=75.35, \quad p<0.001$; temperature: $F_{2,32}=336.72, p<0.001$; photoperiod $\times$ temperature: $\left.F_{2,32}=38.62, p<0.001\right)$.

The cumulative emergence curve for $C$. pubicornis females held at $15^{\circ} \mathrm{C}$ and the two experimental photoperiods is shown in Fig. 2. At the other tem-

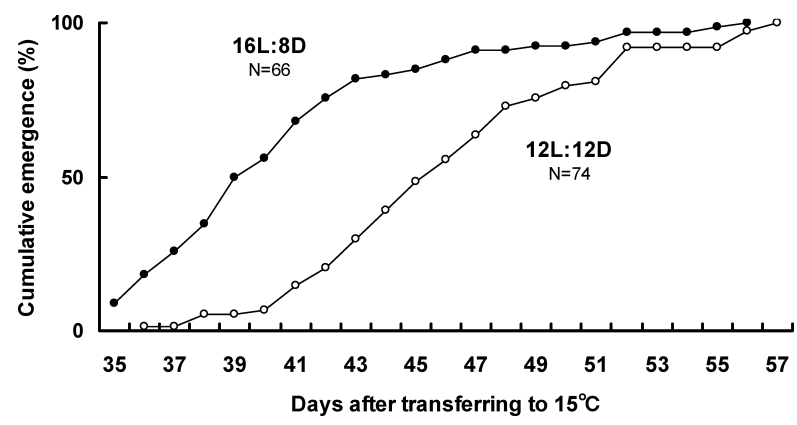

Fig. 2. Cumulative emergence of $C$. pubicornis females from diapausing larvae stored for three months at $25^{\circ} \mathrm{C}$ and $16 \mathrm{~L}: 8 \mathrm{D}$ and then transferred to $15^{\circ} \mathrm{C}$ and either short (12L:12D) or long (16L:8D) photoperiod.

peratures, too few individuals emerged in at least one of the photoperiods tested. The emergence of wasps at $15^{\circ} \mathrm{C}$ lasted 22 days in both short and long photoperiods; however, the photoperiod clearly affected the emergence pattern of wasps at this temperature. At $16 \mathrm{~L}: 8 \mathrm{D}$, the cumulative emergence increased rapidly during the first nine days (35-43 days after transfer to $15^{\circ} \mathrm{C}$ ) and slowly during the rest of the emergence period. On the other hand, at $12 \mathrm{~L}: 12 \mathrm{D}$, cumulative emergence increased slowly in the first five days (36-40 days after transfer to $\left.15^{\circ} \mathrm{C}\right)$, and rapidly from day 6 to $13(41-52$ days after transfer), and slowly again for the remaining part of the period. There was a significant difference in the mean time to the emergence of wasps between photoperiods ( $p<0.001$, Student's $t$ test), with $40.8 \pm 0.63$ (mean \pm SE) and $46.3 \pm 0.56$ days after transfer to $15^{\circ} \mathrm{C}$ at $16 \mathrm{~L}: 8 \mathrm{D}$ and $12 \mathrm{~L}: 12 \mathrm{D}$, respectively.

Table 3 shows an estimation of the time individuals needed to terminate diapause and pupate, and the mean time to adult emergence after diapausing larvae were transferred to either $15^{\circ} \mathrm{C}$ or $20^{\circ} \mathrm{C}$ under 12L:12D photoperiod. Males emerged earlier than females at both temperatures, and both males and females at $20^{\circ} \mathrm{C}$ emerged earlier than those at $15^{\circ} \mathrm{C}$, respectively. The effect of sex and temperature on the mean time to adult emergence was highly significant, but the interaction had no significant effect (two-way ANOVA, sex: $F_{1,377}=31.41, \quad p<0.001$; temperature: $F_{1,377}=$ 528.48, $p<0.001$; sex $\times$ temperature: $F_{1,377}=0.52$, $p=0.47$ ). The time estimated for diapausing larvae to terminate diapause and pupate was always longer than half of the total time to adult emergence (Table 3). 
Table 3. Total time (days; mean \pm SE) to adult emergence of C. pubicornis adults after exposing diapausing larvae to 15 and $20^{\circ} \mathrm{C}$ and 12L:12D, and estimation of time for diapausing larvae to complete diapause and pupate

\begin{tabular}{|c|c|c|c|c|}
\hline \multirow{2}{*}{$\begin{array}{c}\text { Environmental } \\
\text { conditions }\end{array}$} & \multicolumn{2}{|c|}{ Time to adult emergence } & \multicolumn{2}{|c|}{ Estimated time to pupation ${ }^{\mathrm{a}}$} \\
\hline & $\begin{array}{l}\text { Male } \\
(n)\end{array}$ & $\begin{array}{c}\text { Female } \\
(n)\end{array}$ & Male & Female \\
\hline $15^{\circ} \mathrm{C}, 12 \mathrm{~L}: 12 \mathrm{D}$ & $\begin{array}{c}43.2 \pm 0.61 \\
\quad(78)\end{array}$ & $\begin{array}{c}46.3 \pm 0.56 \\
(74)\end{array}$ & 24.5 & 27.2 \\
\hline $20^{\circ} \mathrm{C}, 12 \mathrm{~L}: 12 \mathrm{D}$ & $\begin{array}{c}32.3 \pm 0.35 \\
\quad(150)\end{array}$ & $\begin{array}{c}34.7 \pm 0.46 \\
(79)\end{array}$ & 19.8 & 22.0 \\
\hline
\end{tabular}

\footnotetext{
${ }^{\text {a }}$ The exact time needed for diapausing larvae to terminate diapause and pupate could not be determined experimentally due to darkening of many host puparia and the surrounding leaf tissue after 3-month storage. The values presented here were estimated by subtracting the nondiapause pupal development period (Table 1) from postdiapause time to adult emergence. The estimation is based on the assumption that the pupal development rate of diapause individuals is similar to that of nondiapause individuals.
}

\section{DISCUSSION}

\section{Effect of temperature on the developmental pe- riod}

The development time of C. pubicornis gradually decreased as temperature increased. Total development times were longer, and the thermal requirements and lower developmental threshold were slightly higher than those reported for its host, C. horticola, by Mizukoshi and Togawa (1999). As a result, C. pubicornis would develop more slowly than its host, as observed in other host-parasitoid relationships (Campbell et al., 1974; Sugimoto et al., 1982; Nealis et al., 1984; Bernal and González, 1993). Campbell et al. (1974) suggested that this may be a mechanism that allows some parasitoids to ensure the continued availability of a minimum host supply, which is particularly important at the beginning of the season since the parasitoid season cannot start earlier than that of its host. Such developmental differences may also suggest that the relationship between C. pubicornis and its host is stable and welladapted.

\section{Effects of photoperiod and temperature on dia- pause induction and termination}

The larval development of $C$. pubicornis was suppressed in a proportion that increased with photoperiod and temperature (Fig. 1A). This apparently occurred at the last larval instar, after feeding was complete. Specific stimuli, i.e. low temperature or a combination of moderate temperature and short photoperiod, were needed for resumption of the development and eventual emergence of adult wasps (Fig. 1B). Such response of larval development to environmental cues is considered characteristic of summer diapause or estivation (Mansingh, 1971; Tauber and Tauber, 1976; Masaki, 1980). The photoperiodic response was affected by temperature, with the diapause induction at $25^{\circ} \mathrm{C}$ being significantly higher than that at the lower temperatures tested (Fig. 1A). The photoperiodic response for diapause termination was not exactly the mirror image of that for diapause induction. From Fig. 1B it is clear that as long as diapausing larvae experience temperatures equal to or greater than $25^{\circ} \mathrm{C}$, there will be no significant diapause termination even with a short photoperiod (12L:12D). When temperature decreases to $20^{\circ} \mathrm{C}$, most individuals will terminate diapause but only with a short photoperiod (12L:12D). As temperature further decreases below $20^{\circ} \mathrm{C}$, the effect of the photoperiod is expected to gradually disappear, so that at $15^{\circ} \mathrm{C}$, temperature alone will stimulate diapause termination. The photoperiod also plays a role in synchronizing and stabilizing the termination of summer diapause (Masaki, 1980). C. pubicornis females that terminated diapause with a short photoperiod (12L:12D) and $15^{\circ} \mathrm{C}$ emerged gradually, while those at the same temperature but with a long photoperiod (16L:8D) emerged earlier and at a relatively faster rate (Fig. 2).

\section{Summer diapause and the life history of $C$. pu- bicornis in southern Japan}

Diapause is an evolutionary adaptation with the primary goal of synchronizing the life cycle of the 
insect with the cycle of food availability (Masaki, 1980). Our results suggest that summer diapause would serve as means for C. pubicornis to cope with scarce food resources during the summer. The main host of $C$. pubicornis, $C$. horticola, infests autumn-sown garden peas and builds up a relatively large population during winter; however, from early spring, it suffers increasing mortality by a species-rich parasitoid complex (Fukuhara, unpublished data). C. pubicornis is one of the dominant parasitoid species from late February throughout mid April, but its population declines along with that of its host towards the end of the garden pea season in mid- or late May (Fukuhara, unpublished data). After garden peas die off, C. horticola is likely to pass another generation on different host plants, as it does in the Kyoto area, central Japan (Takada and Kamijo, 1979). C. horticola can attack crops and weeds in several plant families (Sasakawa, 1961); however, its development at warm temperatures such as $25^{\circ} \mathrm{C}$ (historical value at the end of June in Miyazaki, Fig. 3) is limited because the adult emergence rate decreases (Mizukoshi and Togawa, 1999). This might partially explain why flies leave agricultural fields during the summer and reappear in early fall, such as in Kyoto (Takada and Kamijo, 1979) and Miyazaki (personal observations). The eventual disappearance of $C$. horticola from agricultural fields throughout the summer represents a lack of adequate food resources for C. pubicornis. Summer

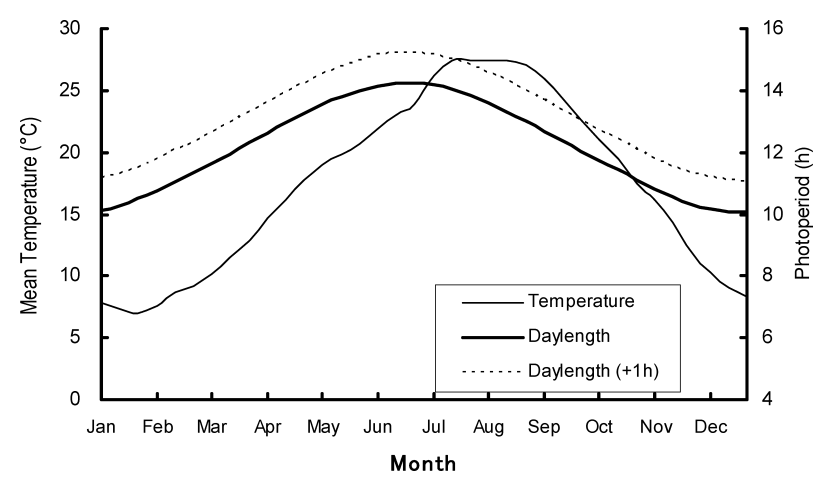

Fig. 3. Annual variation of daylength and mean air temperature in Miyazaki City $\left(31^{\circ} 56.3^{\prime} \mathrm{N}, 131^{\circ} 24.8^{\prime} \mathrm{E}\right)$, Japan. Daylength shown with and without $1 \mathrm{~h}$ of civil twilight (twilight data obtained from the U.S. Naval Observatory Website: http://aa.usno.navy.mil/ and approximated to $1 \mathrm{~h}$ ). Air temperature data are mean daily values from 1970-2000 (data obtained from the Japan Meteorological Agency Website: www.jma.go.jp). diapause would then play a key role in the life history of this parasitic wasp, by allowing larvae developing in late spring to survive the summer months in a state of suppressed development inside the host puparium.

The timing of $C$. pubicornis diapause induction and termination in the field can be estimated based on the results of this study and data for temperature and daylength (with $1 \mathrm{~h}$ of civil twilight added) in Miyazaki City (Fig. 3). The first diapause-inducing stimuli may occur around mid-April, when the daylength is $14 \mathrm{~h}$ and temperature about $16^{\circ} \mathrm{C}$ (Fig. 1A, Fig. 3). From then onwards, an increasing proportion of individuals in the susceptible stage to diapause induction would enter diapause as the photoperiod and temperature increase. By the end of June, when daylength peaks at $15.25 \mathrm{~h}$ and temperature reaches $25^{\circ} \mathrm{C}$, more than half of individuals that may still be developing in the field are expected to enter diapause, but certainly not $100 \%$ of them (Figs. 1, 3). Nondiapause individuals emerging from July and during the rest of the summer (if any) may continue reproduction, but there has not been any survey on the availability of leafminer hosts during this season.

Diapausing larvae in the field are likely to perceive the first stimuli to terminate diapause from mid-September to early October, when daylength shortens from $13.5 \mathrm{~h}$ to $12.5 \mathrm{~h}$ and temperature decreases from 25 to $20^{\circ} \mathrm{C}$ (Figs. 1, 3). From this point onwards, an increasing proportion of individuals are expected to terminate diapause as temperature and daylength continue to decrease. Considering the temperatures prevailing in October and November (approximately $20^{\circ} \mathrm{C}$ and $15^{\circ} \mathrm{C}$ respectively, Fig. 3) and their effect on the postdiapause time to adult emergence (Table 3), it is reasonable to expect the first individuals to emerge from midto late November. Emergence will progress rather slowly due to the low temperatures prevailing and to the effect of short daylength on diapause termination (Fig. 2). The timing and rate of wasp emergence would contribute to ensure host availability for C. pubicornis. C. horticola larvae can be firstly observed mining cabbages and radishes in early or mid-October (unpublished observation). Thus, by the time $C$. pubicornis adults appear in the field, suitable host stages for parasitization are likely to become increasingly available.

Further research is needed to clarify the life his- 
tory strategy of $C$. pubicornis during summer. Surveys of alternate $C$. horticola host plants will confirm if there is an additional generation of C. horticola and its parasitoids after the garden pea season. Field tests would be helpful to determine whether there is a proportion of the C. pubicornis population that does not diapause in summer but continues reproduction in an alternate host, which would suggest a risk-spreading strategy used by some species with facultative diapause (Hopper, 1999). In addition, to better understanding the processes of diapause induction and termination, it is considered essential to determine the sensitive stage to diapause induction and the minimum period that diapausing larvae need to spend under diapause-terminating conditions to complete diapause.

\section{Implications of summer diapause in leafminer parasitoid surveys}

The occurrence of summer diapause in C. pubicornis suggests that the role of this parasitoid species is likely to have been underestimated in surveys of Agromyzid leafminer parasitoids when samples are held in the laboratory under summer diapause-inducing conditions (e.g. the widely used $25^{\circ} \mathrm{C}-16 \mathrm{~L}$ :8D combination). Depending on the developmental stage at which $C$. pubicornis is collected in the field, the susceptible stage to diapause-inducing conditions, and the photoperiodic response of the local population, a proportion of individuals in those surveys may have not emerged as adults but remained as diapausing larvae inside the host puparia. Therefore, to evaluate the role of parasitoids that might enter summer diapause, the photoperiodic response of the species under study should be examined, and the rearing conditions should be selected accordingly.

\section{ACKNOWLEDGEMENTS}

We are grateful to Miss Aiko Ogura for coordinating the kidney bean-growing activities and for her crucial role in establishing the leafminer colony. Mr. A. Shigaki helped to maintain the garden pea leafminer colony, and Mr. K. Takamatsu and Mr. D. Sakai collaborated in leafminer and parasitoid field collections. We also thank two anonymous reviewers, whose valuable comments and suggestions significantly contributed to improve earlier versions of the manuscript.

\section{REFERENCES}

Bazzocchi, G. G., A. Lanzoni, G. Burgio and M. R. Fiacconi (2003) Effects of temperature and host on the pre-ima- ginal development of the parasitoid Diglyphus isaea (Hymenoptera: Eulophidae). Biol. Control 26: 74-82.

Bernal, J. and D. González (1993) Temperature requirements of four parasites of the Russian wheat aphid Diuraphis noxia. Entomol. Exp. Appl. 69: 173-182.

Cameron, E. (1939) The holly leaf-miner (Phytomyza ilicis, Curt.) and its parasites. Bull. Entomol. Res. 30: 173208.

Campbell, A., B. D. Frazer, N. Gilbert, A. P. Gutierrez and M. Mackauer (1974) Temperature requirements of some aphids and their parasites. J. Appl. Ecol. 11: 431-438.

Cornelius, S. J. and H. C. J. Godfray (1984) Natural parasitism of the chrysanthemum leaf-miner Chromatomyia syngenesiae H. (Dipt.: Agromyzidae). Entomophaga 29: 341-345.

Dangerfield, P. C., A. D. Austin and G. L. Baker (2001) Biology, Ecology and Systematics of Australian Scelio: Wasp Parasitoids of Locust and Grasshopper Eggs. CSIRO Publishing, Collingwood, Australia. 264 pp.

Hansson, C. (1987) Revision of the New World species of Chrysocharis Forster, 1856 (Hymenoptera: Eulophidae). Entomol. Scand. Suppl. 31: 1-86.

Hopper, K. R. (1999) Risk-spreading and bet-hedging in insect population biology. Annu. Rev. Entomol. 44: 535-560.

Ikeda, E. (1996) Revision of the Japanese species of Chrysocharis (Hymenoptera, Eulophidae), III. Jpn. J. Entomol. 64: 551-569.

Kamijo, K. (1978) Chalcidoid parasites (Hymenoptera) of Agromyzidae in Japan, with description of a new species. Kontyû 46: 455-469.

Kato, M. (1996) Effects of parasitoid community structure upon the population dynamics of the honeysuckle leafminer, Chromatomyia suikazurae (Diptera: Agromyzidae). Res. Popul. Ecol. 38: 27-40.

Mansingh, A. (1971) Physiological classification of dormancies in insects. Can. Entomol. 103: 983-1009.

Masaki, S. (1980) Summer diapause. Annu. Rev. Entomol. 25: $1-25$.

Minkenberg, O. P. J. M. (1990) On seasonal inoculative biological control. Univ. Wageningen $\mathrm{PhD}$ thesis, Netherlands. $230 \mathrm{pp}$.

Mitsuda, K. and Y. Yamasaki (2003) Parasitoid complex serpentine leafminer (Liriomyza trifolii (Burguess)) in Ehime Prefecture. Bulletin of the Ehime Agricultural Experimental Station 37: 35-39 (in Japanese with English summary).

Mizukoshi, T. and H. Togawa (1999) Developmental zero, effective accumulative temperature, and number of annual generations of the garden pea leafminer, Chromatomyia horticola Goureau (Diptera: Agromyzidae) in the Oshima District of Hokkaido. Annu. Rep. Soc. Plant Prot. North Japan 50: 169-172 (in Japanese with English summary).

Nealis, V. G., R. E. Jones and W. G. Wellington (1984) Temperature and development in host-parasite relationships. Oecologia 61: 224-229.

Ohno, K., D. Yamaguchi, N. Maryana, K. Takesaki and H. Takemoto (1999) Reproductive efficiency of Eulophid 
parasitoids (Hymenoptera: Eulophidae) attacking the larvae of Liriomyza trifolii (Diptera: Agromyzidae). Jpn. J. Entomol. (N.S.) 2: 1-9 (in Japanese with English summary).

Polgar, L. A. and J. Hardie (2000) Diapause induction in aphid parasitoids. Entomol. Exp. Appl. 97: 21-27.

Radcliffe, E. B. and K. L. Flanders (1998) Biological control of alfalfa weevil in North America. Int. Pest Manag. Rev. 3: 225-242.

Sasakawa, M. (1961) A study of the Japanese Agromyzidae (Diptera). Part III. Sci. Rep. Kyoto Pref. Univ. Agric. 13: 60-67.

Sugimoto, T. and I. Masaki (1979) Mortality of a ranunculus leaf mining fly, Phytomyza ranunculi (Diptera: Agromyzidae), due to parasitization and host-feeding by its Eulophid parasite, Chrysocharis pentheus (Hymenoptera: Eulophidae). Appl. Entomol. Zool. 14:
$410-418$.

Sugimoto, T., I. Yasuda, M. Ono and S. Matsunaga (1982) Occurrence of a ranunculus leaf-mining fly, Phytomyza ranunculi and its Eulophid parasitoids from fall to summer in the low land. Appl. Entomol. Zool. 17: 139-143.

Takada, H. and J. Kamijo (1979) Parasite complex of the garden pea leaf-miner, Phytomyza horticola Goureau, in Japan. Kontyû 47: 18-37.

Tauber, M. J. and C. A. Tauber (1976) Insect seasonality: diapause maintenance, termination, and postdiapause development. Annu. Rev. Entomol. 21: 81-107.

Tsukada, M. (1999) Interpopulation variation of hibernalaestival diapause in the egg parasitoid wasp Anagrus takeyanus: adaptation to seasonal host-plant alternation of the tinged host, Stephanitis takeyai. Entomol. Exp. Appl. 92: 37-43. 